\title{
A conceptual model for the long term evolution of tidal flats in the Venice lagoon
}

\author{
L. Carniello, L. D’Alpaos \& A. Defina \\ Department IMAGE, University of Padova, Padova, Italy
}

\author{
S. Fagherazzi \\ Department of Earth Sciences and Center for Computational Science, Boston University, \\ Boston, Massachusetts, US
}

\begin{abstract}
Shallow tidal basins like the Venice lagoon, Italy, are often characterized by extensive tidal flats and salt marshes that lie within specific ranges of elevation. Tidal flats lie just below the mean sea level, whereas salt marshes lie at an average elevation higher than mean sea level. Only a small fraction of the tidal basin is characterized by intermediate elevation. Recently a conceptual model has been proposed demonstrating that the bimodal distribution of bottom elevations stems from the characteristics of wave induced sediment resuspension. The model shows that the morphodynamic processes responsible for sediment deposition and erosion produce either tidal flats or salt marshes but no landforms located in the above intermediate range of elevations which comes out to be inherently unstable. The conceptual model has been validated through comparison with numerical results obtained with a two-dimensional wind waves - tidal model applied to the lagoon of Venice. In this work we propose a new framework to explain the long-term evolution of tidal flats in shallow basins. This framework is verified by the application of the conceptual model to different bathymetries of the Venice lagoon reproducing configurations of the lagoon during the last century. The variation displayed by the bottom elevation PDF curve of the Venice lagoon in the last century shows that the lagoon experienced an initial salt marsh degradation phase followed by tidal flat deepening. This result enable us to infer the likely future trend of the Venice lagoon and to suggest the possible morphological consequence of an increased sediment supply induced to face the actual lagoon degradation.
\end{abstract}

\section{INTRODUCTION}

Shallow tidal basins are often characterized by extensive tidal flats and marshes dissected by an intricate network of channels (Rinaldo et al. 1999a, b, Fagherazzi 1999, Defina 2000, Marani et al. 2003) Both tidal flats and salt marshes are prevalently flat landforms located in the intertidal zone. Tidal flats lie below mean sea level, and only the lowest tides expose their surface. Salt marshes have an elevation higher than the mean sea level, are flooded during high tides, and sustain a dense vegetation canopy of halophyte plants that withstand the relative infrequent flooding periods.

A typical intertidal landscape can be found in the Venice lagoon, Italy, where tidal flats and salt marshes are separated by a well defined scarp. The distribution of elevations in the Venice lagoon shows that tidal flats have differences in elevation of few tens of centimeters, with an average elevation between -0.6 and $-2.0 \mathrm{~m}$ above the mean sea level ( $\mathrm{m}$ a.m.s.l.), whereas salt marshes lie at an average elevation higher than $+0.1 \mathrm{~m}$ a.m.s.1., with some variability dictated by local sedimentological and ecological conditions. Few areas are located at intermediate elevations (i.e. between $-0.6 \mathrm{~m}$ and $+0.1 \mathrm{~m}$ a.m.s.l.), suggesting that the processes responsible for sediment deposition and erosion produce either tidal flats or salt marshes but few landforms located in the above critical range of elevations.

In shallow lagoons tidal currents drive morphological evolution only in the channels and in deep areas where the corresponding shear stresses are high enough to resuspend sediments. In shallow areas is instead decisive the role of sediment resuspension by wind waves (Carniello et al. 2005). All the same tidal currents are important in enhancing the bottom shear stress due to wind waves, since the nonlinear interaction between the wave and current boundary layers increase the shear stress beyond the sum of the two singular contributions (Soulsby 1995, 1997).

A conceptual model explaining the transition between tidal flats and salt marshes has recently been 
proposed by Fagherazzi et al. (2006). The model shows that areas with elevations in the critical range (i.e., between $-0.6 \mathrm{~m}$ and $+0.1 \mathrm{~m}$ a.m.s.l. for the lagoon of Venice) are inherently unstable and tend to become either tidal flats or salt marshes. In the present paper, the above conceptual model is applied to the specific case of the Venice Lagoon and validated using the results of a complete coupled wind wave - tidal model.

\section{MATHEMATICAL MODELS}

\subsection{The wind waves - tidal model}

In the following we briefly summarize the coupled wind waves-tidal model (Carniello et al. 2005) used to validate the conceptual model.

The coupled wind waves-tidal model is composed of a hydrodynamic module and a wind wave module. The hydrodynamic module solves the twodimensional shallow water equations modified to deal with flooding and drying processes in irregular domains (D’Alpaos \& Defina 1993, 1995, Defina 2000). The two-dimensional equations solved by the hydrodynamic model using a semi-implicit staggered finite element method are:

$$
\begin{aligned}
& \frac{\partial q_{x}}{\partial t}+\frac{\partial}{\partial x}\left(\frac{q_{x}^{2}}{Y}\right)+\frac{\partial}{\partial y}\left(\frac{q_{x} q_{y}}{Y}\right)-\left(\frac{\partial R_{x x}}{\partial x}+\frac{\partial R_{x y}}{\partial y}\right) \\
& +\frac{\tau_{b x}}{\rho}-\frac{\tau_{w x}}{\rho}+g Y \frac{\partial h}{\partial x}=0 \\
& \frac{\partial q_{y}}{\partial t}+\frac{\partial}{\partial x}\left(\frac{q_{x} q_{y}}{Y}\right)+\frac{\partial}{\partial y}\left(\frac{q_{y}^{2}}{Y}\right)-\left(\frac{\partial R_{x y}}{\partial x}+\frac{\partial R_{y y}}{\partial y}\right) \\
& +\frac{\tau_{b y}}{\rho}-\frac{\tau_{w y}}{\rho}+g Y \frac{\partial h}{\partial y}=0 \\
& \eta \frac{\partial h}{\partial t}+\frac{\partial q_{x}}{\partial x}+\frac{\partial q_{y}}{\partial y}=0
\end{aligned}
$$

where $t$ denotes time, $q_{x}, q_{y}$ are the flow rates per unit width in the $x, y$ (planform) directions respectively, $R_{i j}$ are the Reynolds stresses $(i, j$ denoting either the $x$ or $y$ co-ordinates $), \tau_{b, \text { curr }}=\left(\tau_{b x}, \tau_{b y}\right)$ is the stress at the bottom produced by the tidal current, $\tau_{w}=\left(\tau_{w x}, \tau_{w y}\right)$ is the wind shear stress at the free surface, $\rho$ is fluid density, $h$ is free surface elevation, and $g$ is gravity. $Y$ is the effective water depth, defined as the volume of water per unit area actually ponding the bottom, $\eta$ is the local fraction of wetted domain and accounts for the actual area that is wetted or dried during the tidal cycle.

At each time step, the hydrodynamic model yields nodal water levels which are used by the wind wave model to assess wave group celerity and bottom influence on wave propagation.
The wind wave module is based on the conservation of the wave action (Hasselmann et al. 1973), which is defined as the ratio of wave energy density $E$ to the wave frequency $\sigma$.

For the case of shallow closed basins, the general spectral formulation of the wave action conservation equation can be simplified. In accordance with Carniello et al. (2005), we assume a monochromatic wave and the direction of wave propagation instantaneously adapted to the wind direction. Furthermore we neglect non linear wave-wave and wave-current interactions.

The wave action conservation equation can thus be written as:

$$
\frac{\partial E}{\partial t}+\frac{\partial}{\partial x} c_{g x} E+\frac{\partial}{\partial y} c_{g y} E=S
$$

It is solved with an upwind finite volume scheme which uses the same computational grid as the hydrodynamic model.

The first term of (4) represents the local rate of change of wave energy density in time, the second and third terms represent the energy convection $\left(c_{g x}\right.$ and $c_{g y}$ are the $x$ and $y$ components of the wave group celerity). The source term $S$ on the right-hand side of (4) describes all the external contributions to wave energy and can be either positive, e.g. wind energy input, or negative, e.g. energy dissipation by bottom friction, whitecapping, and depth-induced breaking.

The wind wave model computes the significant wave height using the linear theory in each computational element at each time step.

In our analyses we are interested in evaluating the total bottom shear stress inside the lagoon. Both tidal currents and wind waves contribute to the production of bottom shear stresses.

Actual bed shear stress under the combined action of waves and currents is enhanced beyond the sum of the two contributions. This occurrence is considered in the model using the empirical formulation suggested by Soulsby (1997).

\subsection{The conceptual model}

Herein the conceptual model describing the critical bifurcation of tidal basins (Fagherazzi et al. 2006, Defina et al. 2007) is only briefly summarized.

In shallow basins waves quickly adapt to external forcing (i.e., the local rate of change of wave energy becomes negligible in a short period of time) and the fetch required to attain fully developed condition is short (a fetch length of $2000 \sim 3000 \mathrm{~m}$ is sufficient for water depths around $1 \mathrm{~m}$ ). Therefore, as a first approximation, we can consider a fully developed fetch unlimited condition to evaluate the local wave field. The conservation equation (4) can thus be reduced 


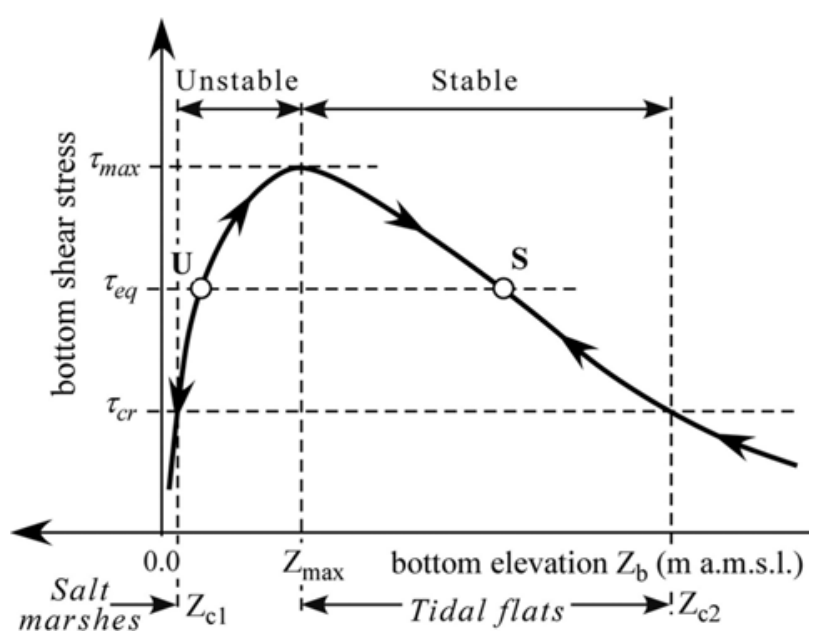

Figure 1. Bed shear stress distribution as a function of bottom elevation.

to the local equilibrium between the source terms i.e. the energy generated by the wind action and the energy dissipated by bottom friction, whitecapping and breaking.

Shear stresses produced by wind waves are limited in shallow waters due to dissipative processes. However, they are also limited in deep water where the bottom is too deep to be affected by wave oscillations. Therefore, plotting the equilibrium shear stress at the bottom as a function of water depth we obtain a curve peaking at some intermediate water depth (Figure 1). It is worth noting that the depth at which the shear stress is maximized is weakly affected by wind speed while variation of the fetch length reduce the amplitude of the curve (Fagherazzi et al. 2006 and Figure 6-inset later in the text).

The model assumes (i) the rate of sediment erosion, $E_{S}$, proportional to the difference between bottom shear stress $\left(\tau_{b}\right)$ and the critical shear stress for sediment erosion $\left(\tau_{c r}\right)$ and (ii) some prescribed average annual sedimentation rate, $D_{S}$, which is site dependent, but yet constant during bottom evolution.

Based on the relationship between shear stress $\left(\tau_{b}\right)$ and bottom elevation (Figure 1), the conceptual model demonstrates that starting from any initial elevation, the final, equilibrium configuration will be either a salt marsh or a tidal flat deeper than $Z_{\max }$ (Figure 1). Defined $E_{S \max }$ as the rate of erosion corresponding to $\tau_{b}=\tau_{\max }$, if deposition exceed this maximum erosion rate (i.e. $D_{S}>E_{S \max }$ ) no equilibrium is possible and vertical accretion of tidal flat eventually will give form to an emergent salt marsh. It is worth noting that the main factors determining the final salt marsh elevation such as sediment supply, organic soil production and sediment compaction are not considered in the conceptual model and therefore a detailed description of salt marsh evolution is beyond the applicability domain of the model. In Figure 1 we can identify three ranges of bottom elevation:

$-\mathrm{Z}_{\mathrm{b}}<\mathrm{Z}_{\mathrm{c} 2}$ : here bed shear stress is smaller than the critical shear stress. In this range of depths $\mathrm{E}_{\mathrm{S}}=0$ and $\mathrm{D}_{S}>0$, thus tidal flats deeper than $\mathrm{Z}_{\mathrm{c} 2}$ evolve toward smaller depths;

$-Z_{b}>Z_{c 1}$ : again bed shear stress is smaller than the critical shear stress. In this case the excess of deposition will lead to a salt marsh;

$-\mathrm{Z}_{\mathrm{c} 2}<\mathrm{Z}_{b}<\mathrm{Z}_{c 1}$ : here, assumed that $\mathrm{D}_{\mathrm{S}}<\mathrm{E}_{\mathrm{Smax}}$, a bed shear stress exists ( $\tau_{\text {eq }}$ in Figure 1 ) such that $E_{S}=D_{S}$ and dynamic equilibrium is possible (points $\mathrm{U}$ and $\mathrm{S}$ in Figure 1). When $\tau_{b}<\tau_{e q}$ deposition exceeds erosion and the bottom evolves toward higher elevations. On the contrary, when $\tau_{b}>\tau_{\text {eq }}$ erosion exceeds deposition and the bottom evolves toward lower elevations (see arrows in Figure 1). It is clear that any point $\mathrm{S}$ on the right branch of the curve is a stable point (any small departure meets conditions that drive the point back toward equilibrium) while any point $U$ on the left branch of the curve is an unstable point (any small departure from point $\mathrm{U}$ meets conditions that drive the bottom elevation away from equilibrium).

Therefore, a stable morphodynamic equilibrium is possible in the ranges $Z_{b}>Z_{c 1}$ pertaining to salt marshes and $Z_{c 2}<Z_{b}<Z_{\max }$ pertaining to tidal flats.

The presence of an unstable branch in the curve of Figure 1 (i.e., $Z_{\max }<Z_{b}<Z_{c 1}$ ) is a very reasonable explanation for the reduced frequency of areas at these intermediate elevations.

\section{APPLICATION TO THE VENICE LAGOON}

The results of two numerical simulations performed with the wind wave - tidal model are used to test the above conceptual model. The first simulation uses a refined mesh that reproduces the present bathymetry of the lagoon of Venice, the second simulation uses the bathymetry of 1901 which is far different from the modern one.

\subsection{0 bathymetry}

In the first simulation a real meteorological event (16-17 February 2003) characterized by Bora wind blowing from North-East at an average speed of approximately $10 \mathrm{~m} / \mathrm{s}$ is simulated. These tidal and meteorological conditions are representative of a typical, morphologically significant, stormy condition for the Venice lagoon.

In the discussion we consider the results computed at $\mathrm{t}=9.00 \mathrm{PM}$ of 16 February 2003 when the water level in the sea is approximately $0.2 \mathrm{~m}$ a.m.s.l. but the water levels in the lagoon are around $0.0 \mathrm{~m}$ a.m.s.l. due to phase lag. 


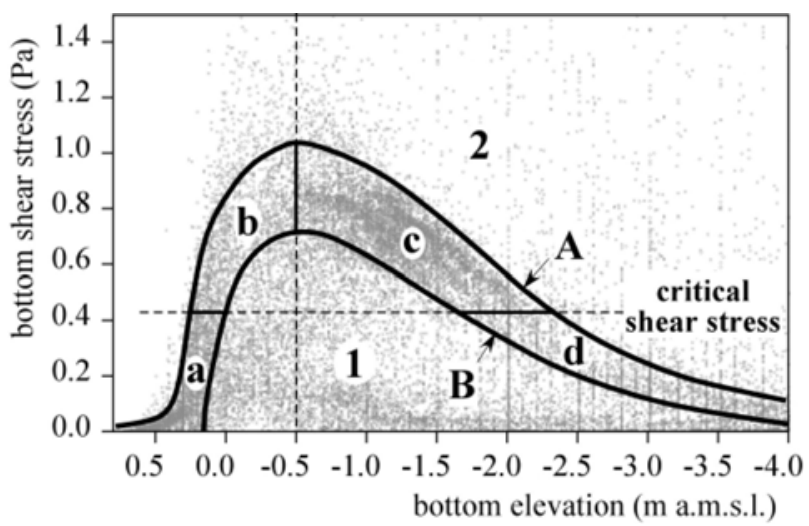

Figure 2. Computed bed shear stress distribution as a function of bottom elevation.

The first part of the analysis is restricted to the central-southern part of the Venice lagoon (South of the city of Venice) where the condition of fully developed wave field (required by the conceptual model) is established over most of the domain.

The computed bottom shear stresses are plotted versus bottom elevations in Figure 2. According to the conceptual model, most of the points should fall along the theoretical curve of Figure 1.

Although the points in Figure 2 display a considerable scatter, most of them are indeed clustered along a curve similar to the theoretical one.

To better analyze the model results, the points plotted in Figure 3 are grouped into six regions defined by: (i) curves A and B that follows the theoretical curve of Figure 1, (ii) the critical shear stress line and (iii) the bottom elevation corresponding to the maximum shear stress, $Z_{\max }$.

We also locate the points plotted in Figure 3 on the map of the Venice lagoon in order to discuss any correlation between the position on the plot and the geographic location.

- Points in region 1 have a bottom shear stress considerably lower than that predicted by the conceptual model. On the map they are located leeward of spits, islands, and emergent salt marshes (Figure 3A) where fetch is limited. This is consistent with the theory if the limiting effects of fetch length were considered (Fagherazzi et al., 2006). As in this part of the analyses we consider only fetch unlimited condition all these points must be removed from the analysis of the conceptual model.

- Points in region 2 have a bottom shear stress greater than the one predicted by the conceptual model. Most of them belong to tidal channels (Figure 3B) where tidal flow concentrates and bed shear stress is mainly due to tidal currents rather than to wind waves. All these point are thus beyond the main assumption of the conceptual model and must be removed from the analysis.

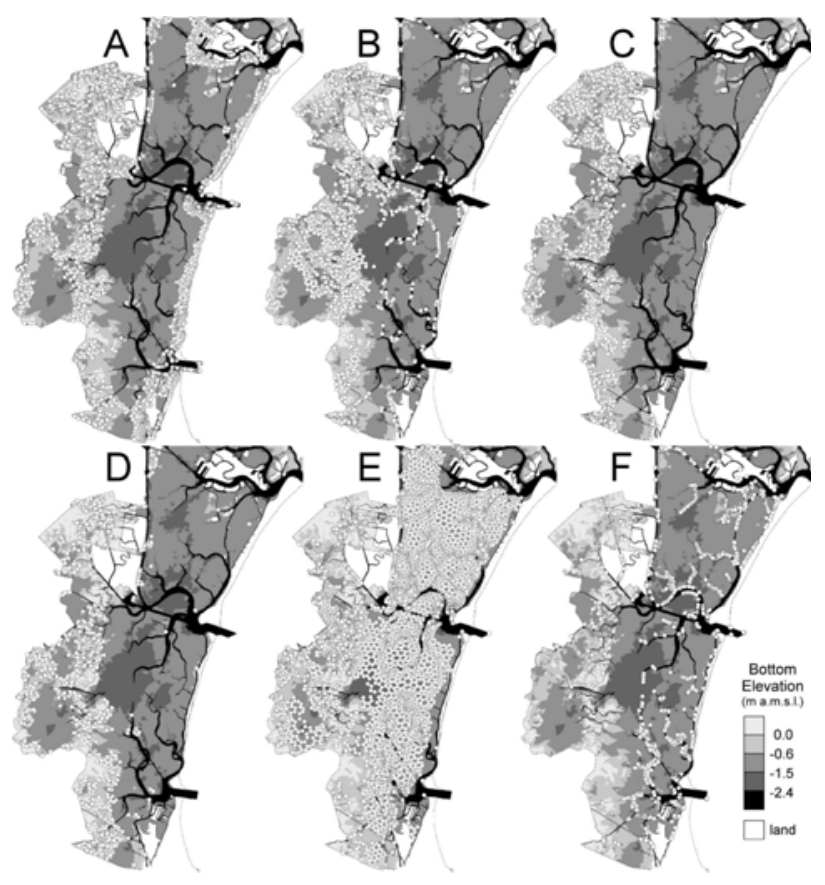

Figure 3. Spatial distribution of basin area following the subdivision indicated in Figure 2: (A) region 1; (B) region 2; (C) region $\mathrm{a}$; (D) region $\mathrm{b}$; $(\mathrm{E})$ region $\mathrm{c} ;(\mathrm{F})$ region $\mathrm{d}$ (each point marks the center of a computational element).

- Points in region a are characterized by a bottom elevation higher than mean sea level. These points are uniformly distributed on salt marshes as shown in Figure 3C.

- Points in region $\mathrm{b}$ belong to the unstable branch of the theoretical curve. According to the conceptual model, few points fall in this unstable region (only $9.2 \%$ of the total area covered by points in the strip). Moreover most of these points are located on tidal flats close to salt marsh edges (Figure 3D). Here, the present lagoon morphology is supposed to be far from equilibrium as salt marshes have been reducing their extent during the last century.

- Points in region c are characterized by bottom elevation lower than the curve peak and bottom shear stress higher than the critical shear stress (i.e. the stable part of the theoretical curve). They are uniformly distributed (Figure 3E) on tidal flats in the central part of the basin; only tidal channels, salt marshes and sheltered regions are not covered by points, in agreement with the theoretical predictions. In addition, the morphological stability of region c can also be argued by the large amount of points falling in this region $(79.5 \%$ of the total area covered by points in the strip).

- Points in region $\mathrm{d}$ are characterized by bottom elevation deeper than $-2.00 \sim-2.50 \mathrm{~m}$ a.m.s.1. The conceptual model predicts no stable tidal flats in this region. Here in fact erosion rate is absent $\left(\tau_{b}<\tau_{c r}\right)$ and any deposition, however small, would 


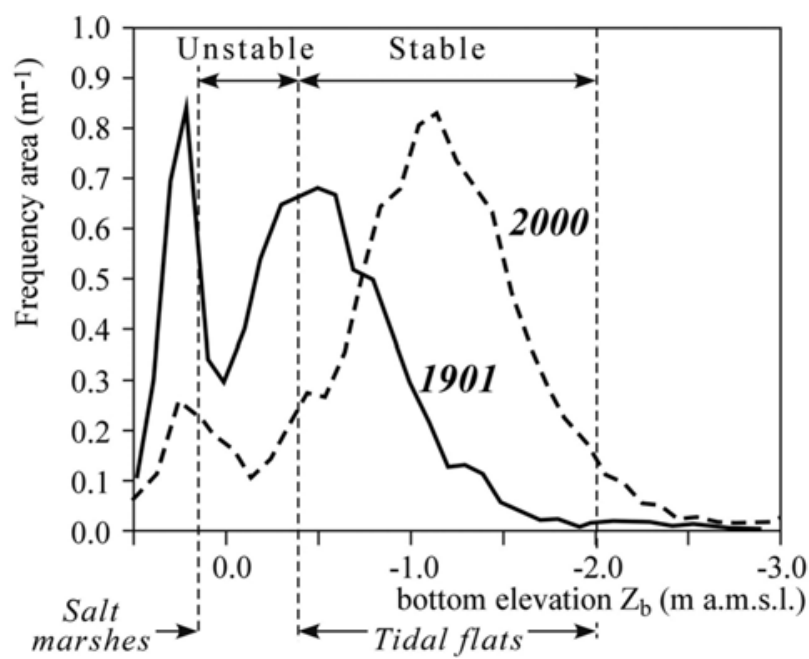

Figure 4. Frequency area distributions as a function of bottom elevation for the Southern Venice lagoon (1901 and 2000 bathymetries).

rapidly infill areas deeper than $-2.00 \sim-2.50 \mathrm{~m}$ a.m.s.l.. Therefore, points in region $\mathrm{d}$ can be either unstable or located in areas beyond the validity range of the model (e.g., tidal channels). Figure 3D shows that the few points in region $\mathrm{d}(2.3 \%$ of total area covered by points in the strip) all belong to tidal channels and must be removed from the analysis.

After removing all the points in regions 1 and 2 we evaluate the bottom elevation PDF curve of the central - southern part of the 2000 Venice lagoon. The curve, plotted in Figure 4 (dashed line), shows the minimum corresponding to elevations in the unstable range thus confirming that just a small fraction of the basin is characterized by these intermediate elevations, in agreement with the conceptual model.

\subsection{1 bathymetry}

A second simulation performed with the wind wave tidal model uses the topography of the Venice lagoon in 1901. A comparison between the 1901 and the 2000 bathymetries is shown in Figure 5. Contrary to the present lagoon morphology, in 1901 salt marshes covered most of the basin while areas occupied by tidal flats were considerably reduced.

The same wind and tidal conditions are applied to the 1901 bathymetry. After removing all points outside the validity range of the conceptual model following the same procedure used for the 2000 lagoon, the frequency area distribution curve is obtained and plotted in Figure 4 (solid line) where it is compared with the one obtained with the modern bathymetry. The minimum within the unstable range of elevations is even more evident in 1901 than in 2000. The peak of the distribution falls near the critical elevation, corresponding to the peak in the wave shear stress

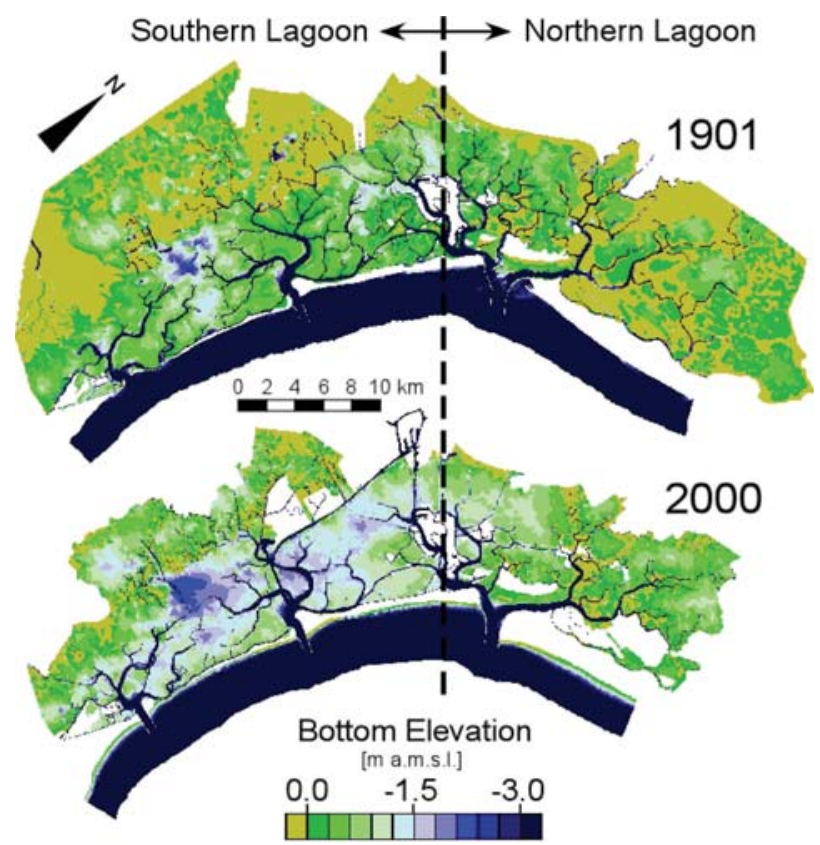

Figure 5. Color scale bathymetry of the Venice lagoon, Italy, in 1901 and in 2000. Elevation is in meters above the mean sea level (m a.m.s.l) actually characterizing the North Adriatic sea at the beginning and at the and of the last century, respectively.

distribution. According to the conceptual model, this means that the average ratio of deposition rate to erosion rate was larger in 1901 than today. In fact, it is commonly stated that the construction, at the beginning of the 19th century, of the long jetties at the three inlets is responsible for the considerable increase of the sediment volume that is exported to the ocean every year.

Relative sea level rise (about $23 \mathrm{~cm}$ for the lagoon of Venice during the last century) has some influence on the deepening of tidal flats which, according to Figure 4, is approximately $70 \mathrm{~cm}$ (Defina et al. 2007).

In the context of the conceptual model, if the sediment supply does not vary, then an increase in water depth due to sea level rise is offset by a decrease in erosion that drives the tidal flat back to its equilibrium water depth.

Analyzing the Exner equation, Defina et al. (2007) demonstrate that sea-level rise acts exactly as erosion does. A moderate sea level rise that does not overtake deposition will merely adjust the tidal flat attracting point (S point in Figure 1) toward positions characterized by a smaller bed shear stress. In fact, if the deposition rate does no vary and the sea level rise acts as a supplementary erosion rate, the wave induced erosion rate actually balancing the deposition rate must be lower. Considering the specific case of the Venice lagoon Defina et al. (2007) estimate that the impact of sea level rise is to increase equilibrium water depth over tidal flats (i.e. to move point $\mathrm{S}$ in Figure 1 toward deeper elevation) of less than $1 \mathrm{~cm}$. 


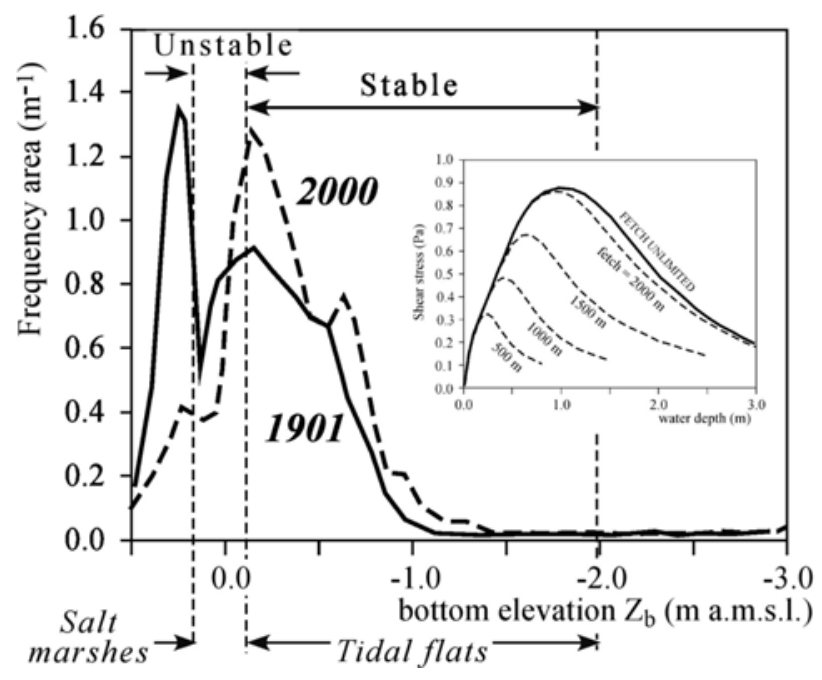

Figure 6. Frequency area distributions as a function of bottom elevation for the Northern Venice lagoon (1901 and 2000 bathymetries).

Therefore, the recorded tidal flats deepening (of approximately $70 \mathrm{~cm}$ ) must be ascribed to a decreased in sediment supply rather than to relative sea-level rise, which only contributed to speed up this evolutionary trend.

\subsection{The northern lagoon}

In the previous paragraphs we concentrate our analysis on the central-southern part of the Venice lagoon where the fetch unlimited condition required by the conceptual model is established over most of the domain.

Here we extend the discussion to the northern part of the lagoon (i.e. North of the city of Venice), again considering both the 1901 and the 2000 bathymetry. In this relative pristine part of the tidal basin the erosion processes are less intense than in the central-southern part. Figure 5 shows that the reduction of the salt marshes extension during the last century is not so evident in the northern lagoon as in the southern.

Because of the presence of well distributed emergent salt marshes the fetch is continuously interrupted and the fetch unlimited condition is almost never reached.

Following the afore described procedure to identify the points that are beyond the validity range of the conceptual model we now must consider in our analyses all the fetch limited points (cfr. region 1 below the theoretical fetch unlimited curve in Figure 3). The only points to be removed are points belonging to tidal channels where the bed shear stress is mainly due to tidal currents rather than to wind waves (cfr. region 2 in Figure 3).

After removing all these points we evaluate the bottom elevation PDF curve of the northern part of the 1901 and 2000 Venice lagoon (Figure 6).
As for the southern lagoon it is evident the bimodal distribution of bottom elevation in accordance with the conceptual model.

The most relevant difference consist in the bottom elevation corresponding to the tidal flat peak. Both the bathymetries in fact display the same value for the depth at which the peak locates, less deep than in the southern lagoon. An explanation stems from the reduction of the fetch. If we consider a fetch limited configuration the peak of the theoretical shear stress versus water depth curve moves towards less deep value (see Figure 5-inset). The bottom elevation of about $-0.3 \mathrm{~m}$ a.m.s.l. characterizing the peaks of the PDF curves correspond to a theoretical curve evaluated considering a $500 \mathrm{~m}$ fetch length which is a reasonable value for the northern part of the Venice lagoon.

\section{IMPLICATIONS FOR THE LONG TERM EVOLUTION OF SHALLOW TIDAL BASINS}

The conceptual model proposed by Fagherazzi et al. (2006) and tested herein bears important consequences for the long term evolution of shallow tidal basins.

Tidal basins are either river paleovalleys drowned after an increase in sea level or coastal areas sheltered by barrier islands and spits. In both cases the tidal basin disconnects the flux of sediments from the incoming rivers to the ocean, by storing and releasing the alluvial and lagoonal sediments with its own specific dynamics. Tidal basins are seldom in equilibrium and are either in aggradation or erosion depending on the balance between the sediment input from the rivers and the output to the ocean driven by tidal currents through the inlets. The alluvial and lagoonal sediments are continuously reworked in the basin by tidal currents and wind waves. Tidal currents are ultimately responsible for the formation of the channels through localized erosion (D'Alpaos et al. 2005) and control the overall sediment fluxes between the basin and the ocean, whereas the diffusive character of the sediment transport triggered by wind waves smoothes bottom topography and builds-up flat landforms that are typical of intertidal environments. In an aggradational setting the initial topography of the basin, which can be relatively ragged in the case of a drowned fluvial valley, becomes more and more gentle in time because of the accumulation and redistribution of sediments at the bottom caused by wind waves. Sediment diffusion by wind waves increases as water depth decreases until, for elevations greater than $Z_{c 2}$, we have the formation of extensive tidal flats. The tidal flat elevation is clustered in a narrow range that, as previously discussed, depends on the balance between erosion, sediment supply and, in case, on the proximity to emergent morphological entities that limit the fetch. 


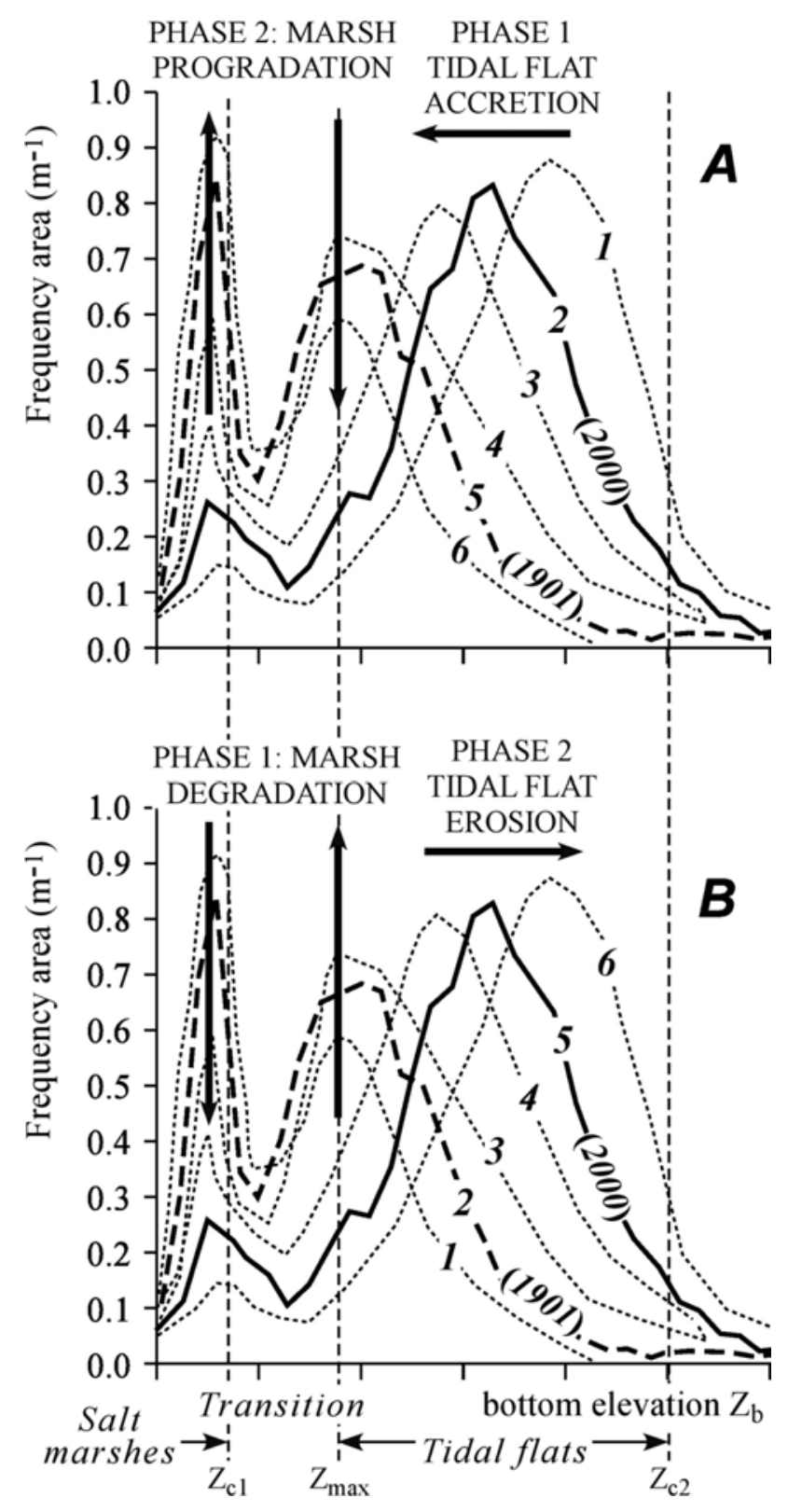

Figure 7. Long term evolution of shallow tidal basins explained through the distribution of basin area as a function of elevation. The solid line is the present area distribution in the southern Venice lagoon, the dashed line is the area distribution in the southern Venice lagoon in 1901 (the dotted lines represent hypothetical stages in time).

If more sediment is accumulated in the basin, the peak of the frequency area distribution shifts towards higher elevations, (Figure 7A, Phase 1). We call this phase tidal flat accretion.

Locally, i.e. in areas far from the inlets and sheltered from wind waves, the maximum erosion rate $E_{S \max }$ is small because of the reduced wave height (e.g., points in region 1 of Figure 3). In these areas deposition rates may thus be larger than $E_{S \max }$ and tidal flats shoal and form a salt marsh (Fagherazzi et al. 2006).

With a larger sediment supply, the peak in area distribution reaches the critical elevation corresponding to the peak in the wave shear stress distribution. Any further net deposition of sediment cannot move the peak to the left, since lower elevations are unstable, and gives rise to new saltmarshes in the basin and to an increase in salt marsh area. The elevation of tidal flats remains locked around the critical elevation and the basin infilling only occurs by expansion of the salt marsh area. We call this phase salt marsh progradation (Figure 7A, Phase 2).

In the same way, in a tidal basin under erosion, we can identify an initial phase in which salt marshes deteriorate and reduce their extension feeding with sediments the neighboring tidal flats which maintain an elevation near the critical one (Figure 7B, Phase 1: marsh degradation). This stage is followed by a phase in which marshes have reduced their extension as much as the sediment supplied to tidal flats is not sufficient to balance tidal flat erosion. As a consequence, the average tidal flat elevation decreases (Figure 7B, Phase 2: tidal flat erosion).

In Figure 6 a sketch reproducing a set of hypothetical bottom elevation PDF curve shows the conceptual model of basin evolution. Among the curves following the above discussed evolution trend the plot put the PDF curve obtained for the 1901 and the 2000 southern lagoon of Venice.

In the light of the above discussion we can interpret the morphological trends of the Venice lagoon. The Southern lagoon in 1901 has a peak in the frequency of tidal flat elevation approximately at $-0.5 \mathrm{~m}$. Since in 1901 large areas of the Southern lagoon were encroached by salt marshes, we can deduce that $Z_{\max }=-0.5 \mathrm{~m}$ is the critical tidal flat elevation and that at the beginning of the last century the incipient loss of sediments, mainly induced by the construction of the jetties at the three inlets, was reflected in a decrease in marsh area.

On the contrary, in 2000 the most frequent tidal flat elevation is approximately $-1 \mathrm{~m}$. This means that at present the basin is already in the phase of vertical tidal flat erosion and the actual further loss of sediments will further deepen the tidal flats and will ultimately lead to a smooth horizontal bottom with elevations around $-2 \mathrm{~m} \sim-2.5 \mathrm{~m}$ a.m.s.1..

In the northern part of the lagoon the observation that during the last century tidal flats have just increased their extension without deepening means that this part of the lagoon is now experiencing the marsh degradation phase. In the erosive scenario characterizing the entire lagoon, we can say that the morphological evolution of the southern lagoon is faster than the one experienced by the northern part.

\section{CONCLUSIONS}

In this work, the conceptual model explaining the mechanism leading to the appearance of tidal flats and 
salt marshes proposed by Fagherazzi et al. (2006) is validated through comparison with numerical results obtained with a two dimensional wind waves - tidal model applied to the lagoon of Venice. The model is forced with real tidal and meteorological conditions which are representative of typical, morphologically significant, stormy conditions for the Venice lagoon.

The computed bottom shear stresses plotted versus bottom elevation show a remarkable concentration of points around the theoretical curve predicted by the conceptual model. Moreover, an analysis of the spatial distribution of shear stresses unable us to identify points that do not meet model hypotheses which cover a small percentage (34\%) of the total area of the tidal basin confirming that the conceptual model actually applies to most of the lagoon. It is further shown that all points falling along the stable branch of the curve are indeed tidal flats, while the few points (less than $10 \%$ of total area) along the unstable branch are located on tidal flats close to salt marsh edges where the present lagoon morphology is likely far from equilibrium since salt marshes are reducing their extension. The above result is also supported by the bottom elevation pdf curves respectively of the northern and southern part of the 1901 and 2000 lagoon (Figures 4-5). The curves show a minimum corresponding to elevations between tidal flats and salt marshes (i.e., in the unstable range of depths).

Based on the conceptual model and the computed frequency area curves, a framework that explains the long-term evolution of shallow tidal basins is finally proposed and discussed. In aggradational conditions first tidal flats accrete until the critical elevation $Z_{\max }$ is reached, and then saltmarshes expand. On the contrary, in an erosional condition, first saltmarshes deteriorate and reduce their extension and then tidal flats deepen. The last condition is more likely the evolutionary trend the lagoon of Venice has been experiencing since the beginning of the last century. In this global trend, however, we can distinguish two different behaviors between the southern and the northern part of the lagoon. The northern part is evolving less faster and is now experiencing a salt marshes deterioration phase while the southern part of the lagoon has already passed over this phase and is now globally deepening.

\section{REFERENCES}

Carniello, L., A. Defina, S. Fagherazzi, \& L. D'Alpaos 2005. A combined wind wave-tidal model for the Venice lagoon, Italy. Journal of Geophysical Research - Earth Surface, Vol. 110, F04007 doi: 10.1029/2004 JF000232.
Defina, A. 2000. Two Dimensional Shallow Flow Equations for Partially Dry Areas. Water Resources Research, vol.36, $11,3251-3264$.

Defina, A., L. Carniello, S. Fagherazzi \& L. D'Alpaos 2007. Self organization of shallow basins in tidal flats and salt marshes. Journal of Geophysical Research - Earth Surface. doi:10.1029/2006JF000550.

D’Alpaos, L. \& A. Defina 1993. Venice lagoon hydrodynamics simulation by coupling 2D and 1D finite element models, Proceedings of the 8th Conference on Finite Elements in Fluids. New trends and Applications, Barcelona (Spain), 20-24 September 1993, p. 917-926.

D’Alpaos, L. \& A. Defina 1995. Modellazione matematica del comportamento idrodinamico di zone a barena solcate da una rete di canali minori, Rapporti e Studi, Ist. Veneto di Scienze, Lettere ed Arti. XII, p. 353-372.

D’Alpaos, A., S. Lanzoni, M. Marani, S. Fagherazzi, \& A. Rinaldo 2005. Tidal network ontogeny: channel initiation and early development, Journal of Geophysical Research - Earth Surface 110, F02001 doi: 10.1029/ 2004JF000182.

Fagherazzi, S., A. Bortoluzzi, W.E. Dietrich, A. Adami, S. Lanzoni, M. Marani, \& A. Rinaldo 1999. Tidal networks 1. Automatic network extraction and preliminary scaling features from Digital Elevation Maps. Water Resources Research, 35(12), p. 3891-3904.

Fagherazzi, S., L. D’Alpaos, L. Carniello, \& A. Defina 2006. Critical bifurcation of shallow basin landforms in tidal flats and salt marshes. Proceedings of the National Academy of Sciences doi:10.1073/pnas.0508379103.

Hasselmann, K., T.P. Barnett, E. Bouws, H. Carlson, D.E. Cartwright, K. Enke, J.A. Ewing, H. Giennapp, D.E. Hasselmann, P. Kruseman, A. Meersburg, P. Muller, D.J. Olbers, K. Richter, W. Sell, \& H. Walden 1973. Measurements of wind-wave growth and swell decay during the Joint North Sea Wave Project (JONSWAP), Dtsch. Hydrogr. Zeit. Suppl., 12(A8), 1-95.

Marani, M., E. Belluco, A. D’Alpaos, A. Defina, S. Lanzoni, \& A. Rinaldo 2003. On the drainage density of tidal networks. Water Resources Research, 39(2), 105-113.

Rinaldo, A., S. Fagherazzi, S. Lanzoni, M. Marani, \& W.E. Dietrich 1999a. Tidal networks 2. Watershed delineation and comparative network morphology. Water Resources Research, 35(12), 3905-3917.

Rinaldo, A., S. Fagherazzi, S. Lanzoni, M. Marani, \& W.E. Dietrich 1999 b Tidal networks 3. Landscape-forming discharges and studies in empirical geomorphic relationships. Water Resources Research, 35(12), 3919-3929.

Soulsby, R.L., 1995. Bed shear-stresses due to combined waves and currents. In: Stive, M.J.F., Fredsoe, J., Hamm, L., Soulsby, R.L., Teisson, C., Winterwerp, J.C. (Eds.), Advances in Coastal Morphodynamics. Delft Hydraulics, Delft, pp. 4-20 - 4-23.

Soulsby, R.L., 1997. Dynamics of marine sands. A manual for practical applications. Thomas Telford Ed. 248 pp. 